\title{
Determining Genetic Diversity of Some Jute Varieties and Accessions Using RAPD Markers
}

\author{
Samiul Haque, Selina Begum, R.H. Sarker ${ }^{1}$ and Haseena Khan ${ }^{* 2}$ \\ Agronomy Division, Bangladesh Jute Research Institute, Dhaka-1207, Bangladesh
}

Key words: Jute, Polymorphism, Genetic diversity, RAPD

\begin{abstract}
The genetic diversity of 18 jute genotypes of the two cultivated species Corchorus capsularis L. and C. olitorius L. which include released varieties and collected races, referred to as accessions was evaluated. DNA profiling was generated using sequence independent RAPD markers. A total of 140 scorable loci were observed and a dendrogram was constructed with these markers. The relationship that is portrayed by this clustering also agreed with the available pedigree information on jute. Two major clusters representing the two species were resolved among the genotypes that were examined in the study. This genetic distance information could be useful in breeding programs in order to introduce agronomically important traits such as short field duration, low temperature tolerance, snow white fibre, higher harvest index etc. From the study one C. olitorius and two C. capsularis varieties were found more suitable for their selection as seed parent against different accessions for improvement because of their higher genetic distant relationship within species. However, more extensive molecular data are needed in order to reach a general conclusion about the relationship between jute genotypes.
\end{abstract}

\section{Introduction}

Bangladesh is the homeland of quality jute production. Jute is a dicotyledonous, self-pollinated fibre yielding plant of the genus Corchorus, transferred recently to the family Malvaceae, from the Tiliaceae (Barbara et al. 2003). Jute fibre is obtained from the bark of the two commercially important species, namely C. capsularis L. (White jute) and C. olitorius L. (Tossa jute). The centre of origin of White jute is said to be Indo-Burma including South China, and Africa for Tossa (Kundu 1951).

Bangladesh holds the largest gene bank of jute and allied fibre (JAF) crops. In the Gene Bank of Bangladesh Jute Research Institute (BJRI) there are 5936 Accessions of jute and allied fibre germplasms comprosing 15 species of

*Author for correspondence: haseena@bangla.net ${ }^{1}$ Department of Botany, University of Dhaka, Bangladesh. ${ }^{2}$ Department of Biochemistry and Molecular Biology, University of Dhaka-1000, Bangladesh. 
Corchorus, 22 species of Hibiscus and 15 of allied genera, yet to be characterized. As jute is largely a self-fertilized crop, its natural genetic variability is very narrow making it difficult for the plant breeders to develop new varieties of this crop through conventional breeding. Use of molecular techniques could be of help in devising strategies to improve the jute crop. However, very little molecular information of jute or its related species is available at the gene bank, and very few efforts have been made in the past to develop molecular markers to study its genetic variability (Hossain et al. 2002, 2003, Roy et al. 2006, Basu et al. 2004). In the previous studies different authors determined the genetic variability of different jute varieties and accessions (collected from various diverse locations) using RAPD and AFLP (Hossain et al. 2002, 2003), STMS, ISSR and RAPD (Roy et al. 2006) and AFLP and SSR markers (Basu et al. 2004). The accessions possessing unique agronomic traits such as snow-white fibre, short field duration (40 - 60 days), low temperature tolerance, waterlogging tolerance etc. along with varieties were incorporated in this study. A similar study was made only with eight Bangladeshi jute varieties (Hossain et al. 2002). In the present study 10 more genotypes (2 new varieties and 8 accessions) were compared with 8 varieties to determine the relative genetic distance within species. The information will be helpful for the breeders for selecting the accession/s as parent to improve the existing varieties because higher genetic distance increases heterosis and selection efficiency.

Differences in DNA sequence are observed as the presence or absence of bands. These differences are characteristic and heritable. The fingerprints can be used to establish the identities of specific DNA samples. The amplification-based scanning methods that use arbitrarily amplified DNA characterize nucleic acids without prior knowledge of nucleotide sequence or cloned and characterized hybridization probes (Livak et al. 1992, Bassam et al. 1992, McClelland et al. 1996). These techniques are versatile and universal, as demonstrated by many applications and wide range of organisms studied (Caetano-Anolles 1996, McClelland et al. 1995).

Randomly amplified polymorphic DNA (RAPD) technique has been used in a wide range of plant species for genetic mapping and gene tagging (Martin et al. 1991, Rafalski et al. 1996), for parentage determination, and for species identification (Welsh et al. 1990). The advantage of using RAPDs in genetic analysis as because it is sequence independent, easy, fast and cost-effective and also requires a small amount of DNA (Welsh et al. 1990).

The present study was undertaken to determine the genetic distance among the varieties and accessions within the same species, which could facilitate the breeder for selecting parents with desired agronomic traits to improve the important agronomic traits among existing varieties. 


\section{Materials and Methods}

A total of 18 jute genotypes (Table 1) comprising six varieties (formally released genotypes for commercial cultivation) and five accessions (any genotype preserved in the gene bank with an entry number) from C. capsularis L. and four varieties and three accessions from C. olitorius L. were used for diversity analysis. From these genotypes, seedlings (obtained from seed germination in Petri dishes at $30^{\circ} \mathrm{C}$ in the dark) were used for DNA isolation.

Table 1. List of 18 genotypes with their origin and unique characters.

\begin{tabular}{|c|c|c|}
\hline $\begin{array}{l}\text { Variety/ } \\
\text { accession }\end{array}$ & Origin & $\begin{array}{l}\text { Unique } \\
\text { characters }\end{array}$ \\
\hline \multicolumn{3}{|l|}{ C. capsularis } \\
\hline Var. D-154 & Local collection, PLS & $\begin{array}{l}\text { Stem green, petiole upper side dull coppery } \\
\text { red, ovate leaves. }\end{array}$ \\
\hline Var. CVL-1 & - do- & Full green, leaves lanceolate. \\
\hline Var. CVE-3 & Thailand, PLS & $\begin{array}{l}\text { Stem green, petiole upper side bright coppery } \\
\text { red. }\end{array}$ \\
\hline Var. CC-45 & Egypt & $\begin{array}{l}\text { Stem green, petiole upper side light coppery } \\
\text { red. Photo insensitive. }\end{array}$ \\
\hline Var. BJC-83 & CVL-1 $\times$ Fuleshori & Full green, leaf blade wavy, leaves tip pointed. \\
\hline Var. BJC-7370 & CC-45 × D-154 & $\begin{array}{l}\text { Stem green, petiole upper side light coppery } \\
\text { red, broader leaves. }\end{array}$ \\
\hline Acc. No. 905 & Japan & $\begin{array}{l}\text { Higher harvest index }(40 \% \text { bark weight basis, } \\
\text { normal } \mathrm{HI} \text { is about } 30-35 \%) \text {. }\end{array}$ \\
\hline Acc. No. 1505 & Local collection & Full green, blue seeded, snow white fibre. \\
\hline Acc. No. 1515 & Nepal & $\begin{array}{l}\text { Short field duration ( } 60-80 \text { days, normal } \\
\text { duration } 120 \text { - } 160 \text { for high yielding varieties). }\end{array}$ \\
\hline Acc. No. 1833 & Local collection & Short field duration (40 - 60 days). \\
\hline Acc. No. 2470 & Local collection & Stem red, water logging tolerant. \\
\hline \multicolumn{3}{|l|}{ C. olitorius } \\
\hline Var. O-4 & Local collection & $\begin{array}{l}\text { Full green, leaves long and broad, } \\
\text { photosensitive }\end{array}$ \\
\hline Var. O-9897 & O-5 × BZ-5 & $\begin{array}{l}\text { Full green, leaves lanceolate, short day } \\
\text { tolerant. }\end{array}$ \\
\hline Var. OM-1 & Uganda PLS & Full green, ovate glossy leaves. \\
\hline Var. O-72 & $\begin{array}{l}(\mathrm{O}-9897 \times \mathrm{O}-2012) \\
\times \mathrm{O}-9897\end{array}$ & Full green, ovate non-glossy leaves. \\
\hline Acc. No. 1333 & Japan & Full green, cylindrical stem. \\
\hline Acc. No. 1805 & Egypt & $\begin{array}{l}\text { Base of stem \& stipule red, low temperature } \\
\text { tolerant. }\end{array}$ \\
\hline Acc. No. 3828 & Local collection & Full green and early maturing. \\
\hline
\end{tabular}

Note: PLS $=$ Pure Line Selection .

DNA extraction and amplification: DNA was extracted from each sample following Doyle and Doyle`s (1990) protocol. DNA samples from 18 jute 
genotypes were amplified with 40 arbitrary decamer primers from Operon Technologies, USA. The reaction mixture $(25 \mu \mathrm{l})$ contained the following: 1X reaction buffer $(20 \mathrm{mM}$ Tris- $\mathrm{HCl} \mathrm{pH} 8.4,50 \mathrm{mM} \mathrm{KCl}), 0.2 \mathrm{mM}$ dNTPs, $2 \mathrm{mM}$ $\mathrm{MgCl}_{2}$, $60 \mathrm{ng}$ primer, 1.0 unit of Taq DNA polymerase, and 25-40 ng genomic DNA. DNA was amplified in a thermal cycler (Eppendorf Mastercycler Gradient) that was programmed as follows: after preheating for $5 \mathrm{~min}$ at $95^{\circ} \mathrm{C} ; 40$ cycles of $1 \mathrm{~min}$ at $95^{\circ} \mathrm{C}$ (denaturation), $1 \mathrm{~min}$ at $40^{\circ} \mathrm{C}$ (annealing) and $2 \mathrm{~min}$ at $72^{\circ} \mathrm{C}$ (extension), and a final extension at $72^{\circ} \mathrm{C}$ for $7 \mathrm{~min}$ that was followed by cooling to $4^{\circ} \mathrm{C}$. Before amplification, all the PCR chemicals and amplification conditions were optimized using different concentration of the ingredients.

Visualizing the PCR products: DNA dye (Xylene cyanol: 0.25\%, bromophenol blue: $0.25 \%$ and glycerol: $30 \%$ ) was added to the amplified PCR product and mixed well with gentle agitation. After a momentary spin the PCR products were loaded in the wells of $2 \%$ agarose gel. Electrophoresis was accomplished at 80 volts. Then the gel was visualized under UV transilluminator followed by staining in ethidium bromide $(0.5 \mu \mathrm{g} / \mathrm{ml})$ for $20-30 \mathrm{~min}$ and destaining in distilled water (Sambrook et al. 1989).

Scoring and analysis of the data: The amplified products were scored for further analysis. During scoring, only intense clearly resolved amplification products that were reproducible in multiple runs were considered for further analysis. The DNA fragments that were amplified by a given primer were scored as ' 1 ' for presence or ' 0 ' for absence of a particular locus for all of the genotypes that were studied. A cluster analysis was accomplished using the software STATISTICA version 3.0 (Stat Soft 1994).

\section{Results and Discussion}

Eighteen genotypes of two species of jute were used in this study. Amplification of the isolated genomic DNA from each of the 10 jute varieties and 8 accessions using all 40 primers, revealed a variety of RAPD patterns (Fig. 1, all figures are not shown). Among the 40 primers, 25 produced amplification but failed to differentiate the species or genotypes within species, 3 failed to amplify and only 12 were able to generate intra- and interspecific polymorphism among the jute genotypes. They were OPAB-03, OPAB-08, OPAB-18, OPG-03, OPG-05, OPG-08, OPG-10, OPH-04, OPH-12, OPH-19, OPQ-16 and OPQ-17.

A total of 140 scorable loci, DNA fragments or RAPD markers were observed, of which 19 or $13.57 \%$ loci did not show polymorphism, 50 or $35.71 \%$ loci showed interspecific polymorphism and the remaining 71 or $50.72 \%$ loci showed polymorphism among the genotypes within both the species.

The number of band differences obtained by the RAPD primers and square Euclidean distances between genotypes is presented in Table 2. It shows two 
triangular sections. The upper portion of the triangle shows the number of band differences between pairs of jute samples, and the lower triangle shows the distances between the jute genotypes, respectively. From the data presented, the molecular markers that were generated can identify DNA of jute varieties and accessions amplified with 12 RAPD primers. The highest number of band differences (31) was found between C. capsularis Accession no. 1833 and C. olitorius Accession No. 1805. The average genetic distance among the C. olitorius genotypes (18 units) was higher than between those of $C$. capsularis (16.40 units) indicating that $C$. olitorius is genetically more diverse. The result could be correlated with the lower percentage ( 3 to 4 ) of outcrossing in C. capsularis as opposed to 8 to $12 \%$ natural cross-pollination within C. olitorius (Ghose and Gupta 1945). This increases the likelihood of cross-fertilization in C. olitorius and hence it has greater genetic variability compared to C. capsularis.

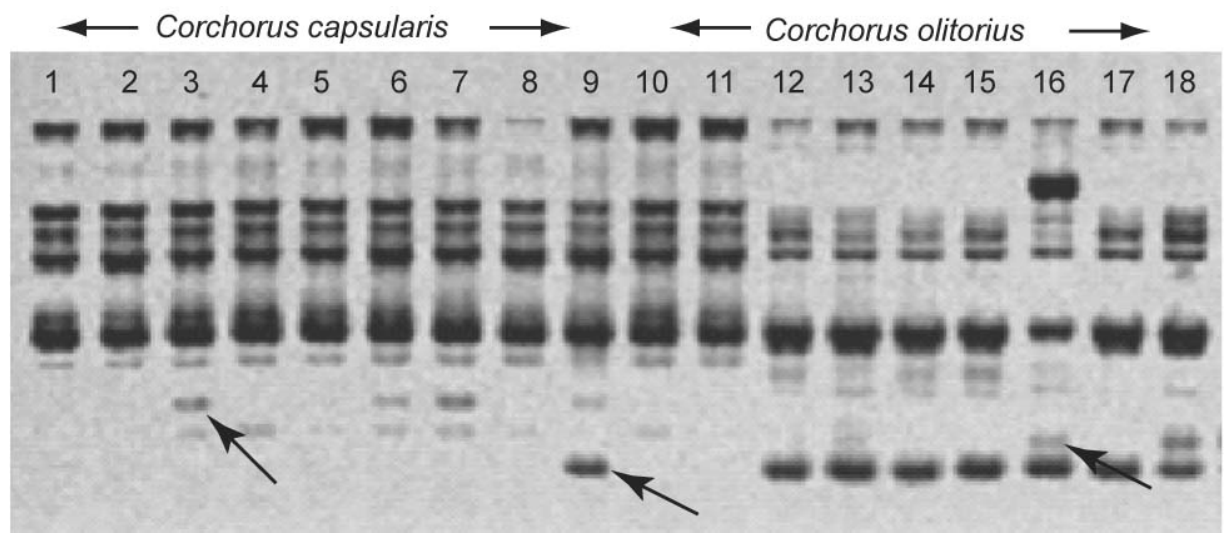

Fig. 1. RAPD profile amplified with primer OPH-12 Arrow indicates inter- and intraspecific polymorphism. 1: Var. D-154, 2: Var. CVL-1, 3: Var. CVE-3, 4: Var. CC-45, 5: BJC-83, 6: BJC-7370, 7: Acc. 905, 8: Acc. 1505, 9: Acc. 1515, 10: Acc. 1833, 11: Acc. 2470, 12: Var. OM-1, 13: Var. O-9897, 14: Var. O-4, 15: Acc. 1333, 16: Acc. 3828, 17: AL. O-72 and 18: Acc. 1805.

DNA fingerprints that were obtained by RAPD analysis revealed that all the 18 genotypes from both species (namely, D-154, CVL-1, CVE-3, CC-45, BJC-83, BJC-7370, Acc. 905, Acc. 1505, Acc.1515, Acc. 1833, Acc. 2470, OM-1, O-9897, O-4, Acc.1333, Acc.3828, O-72. and Acc.1805) were genetically distinct. A dendrogram (Fig. 2) was constructed using the programme STATISTICA, version 3.0 (Stat Soft 1994), based on the genetic distance matrix. The relationship that is portrayed by this clustering also agreed with the available pedigree information (Hossain et al. 2002). Two major clusters representing two species were resolved among the genotypes that were examined in the study. All C. capsularis genotypes belonged to one and those of $\mathrm{C}$. olitorius to the other cluster. The study also revealed that the two jute species are distantly related with a high level of similarity within the species. Presence of distinct patterns of diversity between the two species was 


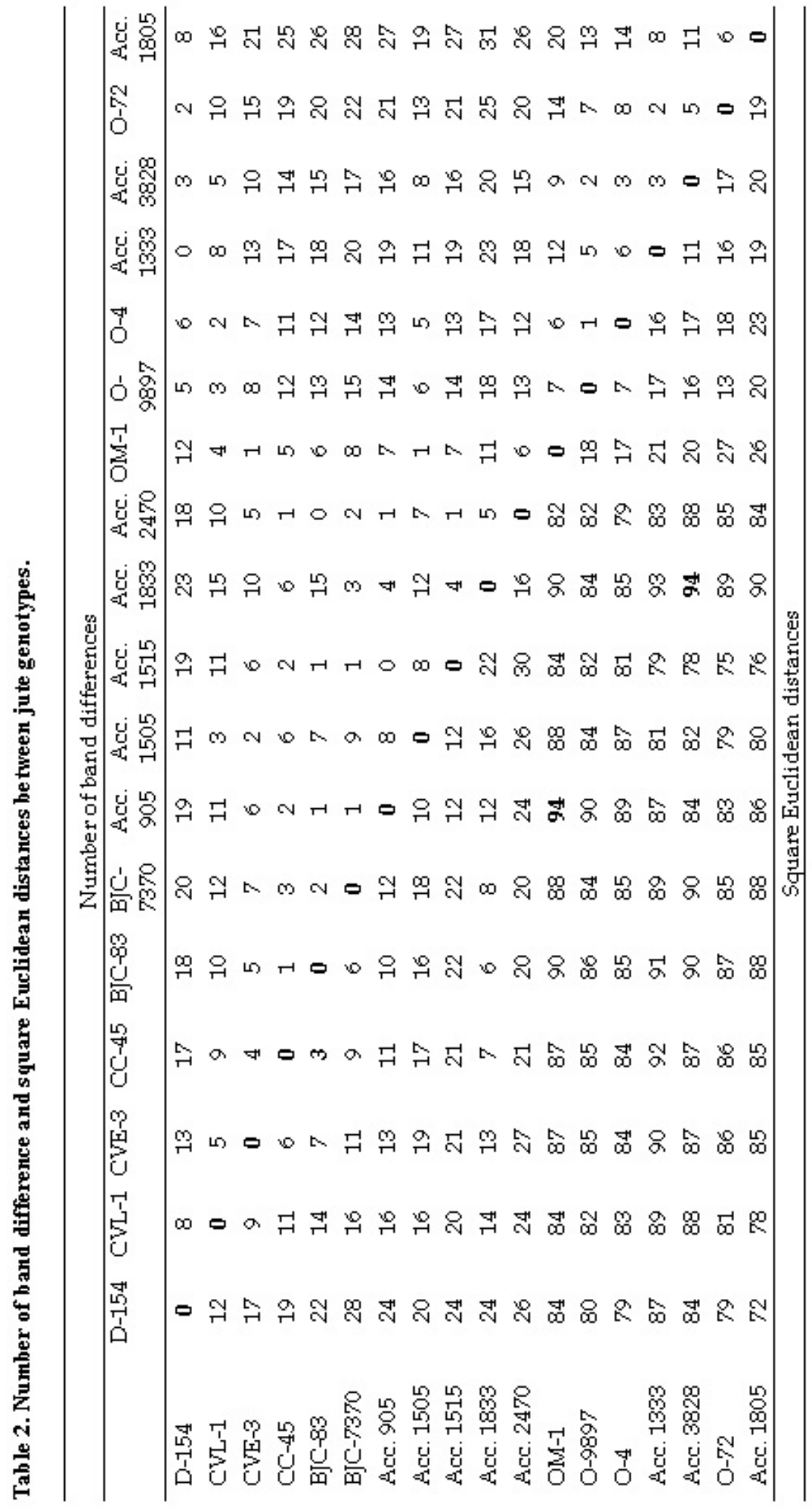


also reported by Palit et al. (1996). Basu et al. (2004) evaluated 49 genotypes collected from 10 different countries including Bangladesh, India, Thailand, Nepal, China, Pakistan, Sudan, Tanzania, Kenya and America for their genetic diversity using SSR and AFLP markers. On the basis of cluster analysis, pair wise genetic distances, the two jute species are widely separated and differences in geographical location of sources did not affect genetic diversity. The results suggesting that the two species are indeed allopatric, sharing certain common alleles. Such distinction provides support to the earlier belief that the two species originated from two different geographical locations (Kundu 1951).

Phylogram of 18 jute genotypes

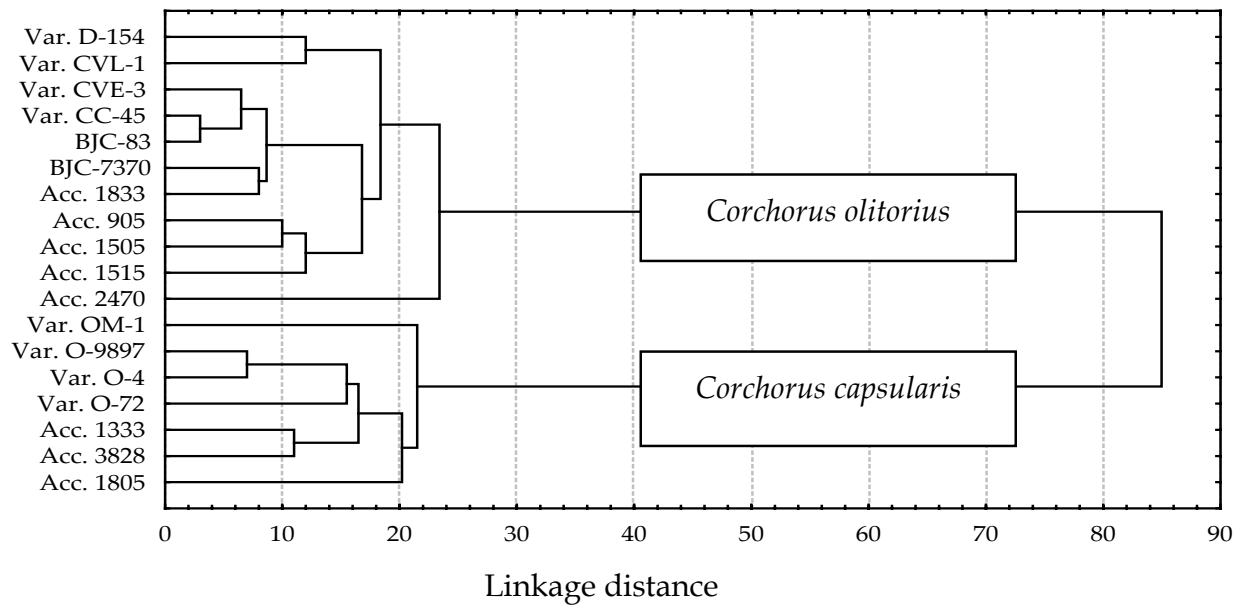

Fig. 2. A dendrogram using RAPD data with cultivars and accessions of jute.

This could be related to the strong sexual incompatibility barrier between these two cultivated jute species, which do not cross-fertilize (Patel and Datta 1960, Swaminathan et al. 1961). But Islam and Rashid (1961), Choudhuri and Mia (1962) have succeeded in producing hybrids. However, all those putative hybrid showed dominance of the female parent in $\mathrm{F}_{1}$ and $\mathrm{F}_{2}$ generations with no varietal release. Raut and Naik (1983) followed the hybrid progenies up to $F_{3}$ generation but there was no further report of exploitation of those hybrids in later generations. This is probably because of the fact that in the later generation the entire population resembled the female parent.

This genetic distance information could be useful in breeding programs in order to introduce agronomically important traits as higher genetic distance increases heterosis and selection efficiency. However, more extensive molecular data are needed in order to make a more general conclusion about the relationship between jute genotypes. From the distance matrix (Table 2) it may be suggested that the breeder selects the C. capsularis variety CVE-3 against Accession No. 2470 for strengthening waterlogging tolerance trait and variety 
D-154 as the seed parent against Accession Nos. 1833, 1505 and 905 for introducing short field duration, snow white fibre and higher harvest index traits respectively to obtain higher heterosis; on the other hand, C. olitorius var. OM-1 may be selected as the seed parent against Accession Nos. 1805, 3828 and 1333 for introducing important agronomic trait/s such as low temperature tolerance, early maturing character and a more cylindrical stem character as the highest genetic distances were observed within these three accessions.

\section{Acknowledgements}

The authors are grateful to the authority of Bangladesh Jute Research Institute (BJRI), for supplying seeds, the University of Dhaka for providing field and laboratory facilities and United States Department of Agriculture (USDA) for financial assistance to carry out this work.

\section{References}

Barbara AW, Kenneth GK and William SA (2003) Chloroplast DNA sequences confirm the placement of the enigmatic Oceanopapaver within Corchorus (Grewioideae: Malvaceae S.L., formerly Tiliaceae). Int. J. Plant Sci. 164 : 35-41.

Bassam BJ, Caetano-Anolles G and Gresshoff PM (1992) DNA amplification fingerprinting of bacteria. Applied Microbiol. Biotech. 38 : 70-76.

Basu A, Ghosh M, Meyer R, Powell W, Basak SL and Sen SK (2004) Analysis of genetic diversity in cultivated jute determined by means of SSR markers and AFLP profiling. Crop Science. 44 : 678-685.

Caetano-Anolles G (1996) Scanning of nucleic acids by in vitro amplification: new developments and applications. Nature Biotechnology. 14 : 1668-1674.

Choudhuri SD and Mia AJ (1962) Species crosses in the genus Corchorus (jute plant). Euphytica. 11: 61-64.

Doyle JJ and Doyle JL (1990) Isolation of plants DNA from fresh tissue. Focus. 12 : 13-15.

Ghose RLM and Gupta BD (1945) Floral biology, anthesis and natural crossing in jute. Indian J. Genet. $4: 80-84$.

Hossain MB, Awal A, Rahman MA, Haque S and Khan H (2003) Distinction between cold-sensitive and - tolerant jute by DNA polymorphisms. J. Biochem. Mol. Biol. 36 : 427-432.

Hossain MB, Haque S and Khan H (2002) DNA fingerprinting of jute germplasm by RAPD. J. Biochem. Mol. Biol. 35 : 414-419.

Islam AS and Rashid A (1961) First successful hybrid between the two jute yielding species, Corchorus olitorius $\times$ C. capsularis. Nature 185: 258-260.

Kundu BC (1951) Origin of Jute. Indian J. Genet. Plant Breed. 11 : 95-99.

Livak KJ, Rafalski JA, Tingey SV and Williams JG (1992) Process for detecting polymorphism on the basis of nucleotide differences. US Patent. 5 : 467-985. 
Martin GB, Williams JGK and Tansley SD (1991) Rapid identification of markers linked to a Pseudomonas resistance gene in tomato by using random primers and nearisogenic lines. Proc. Natl. Acad Sci., USA. 88 : 2336-2340.

McClelland M, Mathieu-Daude E and Welsh J (1995) RNA fingerprinting and differential display using arbitrarily primed PCR. Trends in Genetics. $11: 242-246$.

McClelland M, Welsh JT and Sorge JA (1996) Arbitrarily primed polymerase chain reaction method for fingerprinting genomes. US Patent. 5 : 467-985.

Palit P, Sasmal BC and Bhattacharryya AC (1996) Germplasm diversity and estimate of genetic advance of four morpho- physiological traits in a world collection of jute. Euphytica 90: 89-110.

Patel GI and Datta RM (1960) Interspecific hybridization between Corchorus capsularis L. and C. olitorius L. and the cytological basis of incompatibility between them. Euphytica. 9 : 89-110.

Rafalski JA, Tingey SV and Williams JGK (1996) RAPD markers a new technology for genetic mapping and plant breeding. Ag Biotech News and Information. 3 : 645-648.

Raut RN and Naik G (1983) Interspecific hybridization in cultivated jute. Proc. FAO expert consultation on jute and kenaf improvement. Calcutta, India.

Roy A, Bandyopadhyay A, Mahapatra AK, Ghosh SK, Singh NK, Bansal KC, Koundal KR and Mahapatra T (2006) Evaluation of genetic diversity of jute (Corchorus species) using STMS, ISSR and RAPD markers. Plant Breeding. 125 : 292-297.

Sambrook J, Fritch EF and Maniatis T (1989) Molecular Cloning: Laboratory Manual. Vol. 1, 2 and 3. Second edition. Cold Spring Harbor Laboratory Press, Cold Spring Harbor. New York. pp: 9. 14-9.22.

Stat Soft (1994) STATISTICA users guide version 4.1. Stat Soft Inc. Tulsa, U.K. pp: 1064.

Swaminathan MS and Iyer RD (1961) Skewed recombination in a rare interspecific jute hybrid. Nature. 192 : 893-894.

Welsh J and McClelland M (1990) Fingerprinting genomes using PCR with arbitrary primers. Nucleic Acids Res. 18 : 7213-7218. 